\title{
LA TEORÍA DE LA HISTORIA EN HONDURAS
}

\author{
Rolando Sierra Fonseca*
}

RESUMEN: Este trabajo sobre la teoría de la historia en Honduras es más aproximativo que conclusivo. Se presentan las principales corrientes y perspectivas que se han desarrollado en Honduras con relación a la interpretación de la historia, como la ilustrada, la positivista y la marxista, ya sea la hecha por pensadores individuales, o por grupos con proyectos intelectuales y políticos, tomando en cuenta que la historiografía hondureña como tal es reciente. Si bien ha habido pensadores que se han dedicado a teorizar sobre la historia, la producción de estudios históricos ha sido escasa en el país. En este sentido se analiza la obra de tres pensadores hondureños: José Cecilio del Valle (1777-1834), Ramón Rosa (1848-1893) y Filánder Díaz Chávez (1922-).

Palabras clave: Historia, Teoría de la historia, Historiografía, Honduras.

ABSTRACT: The present paper about Honduran theory of history is more approximate than conclusive. This article shows the mainstreams and perspectives developed in Honduras, related to history interpretation, such as the despotic, the positivist, and the Marxist, made by single thinkers or by groups that had intellectual and political projects, and considering that Honduran historiography as such is recent. That is the way that the works of three Honduras thinkers are explored: José Cecilio del Valle (17771834), Ramón Rosa (1848-1993) and Filánder Díaz Chávez (1922-).

KEYES WORDS: History, Theory of history, Historiography, Honduras.

\section{INTRODUCCIÓN}

Al iniciar el siglo XXI en Honduras la disciplina histórica entra en un relativo proceso de consolidación y de renovación en cuanto a sus objetos de estudio y metodologías, siendo que su origen y desarrollo es reciente dentro del área de las Ciencias Sociales en el país; sin embar-

\footnotetext{
*Universidad Nacional Autónoma de Honduras (rsierra652003@yahoo.com).
} 
go, en este proceso de renovación de la disciplina histórica, hay un campo que no ha sido igualmente estudiado y profundizado: el de la teoría de la historia, es decir, lo que Joseph Fontana ha llamado el pensamiento del que se sirven efectivamente los historiadores para orientar su trabajo, y las ideas sociales subyacentes, las que contienen el proyecto social en que los historiadores inscriben su tarea. ${ }^{1}$

La reflexión sobre la teoría de la historia en Honduras, a mi modo de ver, tiene que partir de uno de los pocos consensos que en los inicios de este nuevo siglo parece existir entre los historiadores, y éste consiste en que lejos de la arrogancia positivista, el conocimiento del pasado es algo condicionado y mediatizado por el propio lugar que ocupa cada uno en el mundo.

El conocimiento histórico, hoy en día, se ha vuelto, por decirlo de una manera, menos arrogante, aunque sin perder sus aspiraciones científicas. Por ello cada vez más se recurre al fragmento y cada vez menos se construyen grandes relatos históricos.

La pretensión de que con el conocimiento histórico se entendería mejor el presente $y$, sobre todo, se posibilitaría prever el futuro tiene que ser más modesta. Lo cual resulta, sin duda alguna, dentro del contexto del desarrollo de las ciencias históricas de un país como Honduras un tanto paradójica: ya que, en el inicio de un nuevo siglo la historia y la teoría de la historia cuentan, por un lado, con una mejor infraestructura y por otro, con una producción de conocimiento histórico cuantitativa y cualitativamente superior que apenas hace unas décadas.

En este trabajo se presentan las principales corrientes y perspectivas que se han desarrollado en Honduras con relación a la interpretación de la historia, ya sea por pensadores individuales, o por grupos con proyectos intelectuales y políticos. De hecho una de las características de la teoría de la historia en Honduras es que se ha utilizado en función de otras actividades como las periodísticas, económicas, políti-

1 Joseph Fontana, Historia, análisis del pasado y proyecto social, Barcelona, Crítica, 1982, p. 9. 
cas y literarias. En este sentido, el conocimiento del pasado se concibe en su relación con el presente y no por el pasado mismo.

Es importante decir que la historiografía hondureña es reciente. Si bien ha habido pensadores que se han dedicado a teorizar sobre la historia, la producción de estudios históricos ha sido escasa en el país. Ha correspondido a la Academia Hondureña de Geografía e Historia, fundada en 1926, la principal labor en la generación del conocimiento histórico y no será hasta 1977 que se crea en la Universidad Nacional Autónoma de Honduras la Carrera de Historia y se inicie como tal la profesionalización de los estudios históricos. Como en muchos países latinoamericanos, la construcción del discurso histórico ha sido hecho por profesionales en los campos de la abogacía, la medicina y la ingeniería.

En el desarrollo de la teoría de la historia en Honduras se pueden distinguir cuatro grandes influencias, que no necesariamente pueden presentarse como etapas en la evolución de un pensamiento: la primera, de la ilustración que puede ubicarse en los inicios del siglo XIX, siendo su principal exponente José Cecilio del Valle; la segunda, corresponde a la del positivismo a finales del siglo XIX y sus principales difusores han sido Ramón Rosa y Adolfo Zúñiga; la tercera, tiene que ver con un cierto esbozo historicista, sobre todo en la primera mitad del siglo Xx y se aprecia en escritores como Miguel Morazán y Rómulo Elpidio Mejía; la cuarta influencia es la marxista, especialmente en la segunda mitad del siglo XX y puede verse en escritores como Filánder Díaz Chávez, Longino Becerra y dentro de la Carrera de Historia de la Universidad Nacional. En este trabajo no se revisará la tercera de ellas referida al historicismo.

\section{LA PeRsPectiva Ilustrada: José Cecilio del Valle}

Para el pensador centroamericano José del Valle (1777-1834), una de sus preocupaciones intelectuales será la del origen y desarrollo de las sociedades, en el entendido que este conocimiento resulta útil a su quehacer político y burocrático. Valle verá en la historia la maestra que alecciona en el ejercicio del gobierno. 
El saber histórico lo relaciona con todas sus otras actividades de funcionario, de periodista, de economista, de político, de naturalista e inclusive de literato, dándole un carácter utilitario al mismo. En este sentido, el conocimiento del pasado lo concibe únicamente en su relación con el presente y no por el pasado mismo.

En el desarrollo de su obra se observan los intentos de articular un conocimiento integral. En este sentido, Valle planificó una obra estructurada en tres sistemas: físico, político y literario. El primero referente a la situación que ocupa el planeta en el espacio, la situación de cada lugar referente al globo; las tierras, piedras, sales, combustibles y metales; las aguas, la atmósfera; las plantas; los animales; el grado de calor, frío, humedad y sequedad y las revoluciones físicas. El político abarcaría la agricultura, industria, comercio, población, gobierno y a las revoluciones políticas. En el literario se encontrarían las ciencias físicas y abstractas y las revoluciones literarias.

De los sistemas físico y literario, se derivan las ciencias físicas y abstractas, sus revoluciones, su decadencia, destrucción y restablecimiento. Este ambicioso proyecto no pudo ser desarrollado debido a que Valle no se limitó a ser un intelectual, sino que era también administrador de sus haciendas y dedicó varios años de su vida al desempeño de cargos públicos en los poderes ejecutivo y legislativo de la Federación Centroamericana. ${ }^{2}$

Dentro de este intento de comprensión holística de la sociedad es que se pretende ubicar y percibir su noción de la historia o en el mejor de los casos la filosofía de la historia de José Cecilio del Valle. Para profundizar en la teoría de la historia de éste es importante tomar en cuenta los siguientes presupuestos de análisis de su pensamiento:

1) El sujeto histórico fundamental para Valle es la naturaleza humana, por lo cual entra en contradicción con las posiciones religiosas o

2 Ramón Oquelí, "Algunos inéditos de José Cecilio del Valle", en Escritos inéditos de José Cecilio del Valle, Tegucigalpa, scA/Universitaria José Cecilio del Valle/UNESCO, 1996, p. 1. 
providencialistas; 2) el fin político que buscaba Valle en su visión de la historia fue el de consolidar el gobierno; 3) el sujeto histórico, para él, era susceptible de una periodización: de una etapa irracional (oscura como el periodo colonial) y una etapa racional (con la independencia).

\section{La naturaleza humana como sujeto histórico}

Durante el siglo XVIII, la filosofía de la ciencia, en general, y de la historia, en particular, reconocen la experiencia como el eje clave de todo el quehacer científico. La búsqueda de la verdad, en el terreno de la experiencia, no tiene otro recurso que el método inductivo; esta inducción es analítica; de ahí una doble obsesión: descomponer en elementos y remontarse hasta el origen. ${ }^{3}$

Este siglo se convierte, de alguna manera, en el siglo de la ciencia de la historia: por el movimiento mismo del método analítico es el siglo que se pregunta por los orígenes. Surgen diferentes historias: la historia de la tierra, la historia natural y, por supuesto, la historia de las sociedades. Además de los archivos monacales y de las genealogías principescas, surgen historias de los acontecimientos pasados, la historia de las costumbres, es decir, de las civilizaciones. ${ }^{4}$

En este periodo se dimensiona el estudio de la historia de la filosofía y aparece como tal la filosofía de la historia, término creado por Voltaire. Esta filosofía de la historia se apoya en dos bases: la historia sin documentos, deducida, imaginaria, en gran parte, que desde J. B. Vico hasta J. J. Rousseau, y desde Rousseau hasta Hegel mismo, reinventará las etapas de la humanidad primitiva; y junto a ésta la historia con documentos cada vez más precisa. Esa filosofía será para todos los que tienen a la vista el ejemplo de las ciencias, una filosofía de

3 Y. Belabal, Racionalismo, empirismo, ilustración, México, Siglo XXI, 1984, p. 197.

4 Ibid., p. 201. 
los progresos del espíritu humano, incluso si se rehúsan, con Rousseau, a reconocer al mismo tiempo y al mismo ritmo, un progreso moral. ${ }^{5}$

Esta idea del progreso fácilmente se introduce entre los pensadores de la Ilustración; creen que la humanidad avanza gradualmente hacia un estado de ilustración y racionalidad. El hombre es un ser perfectible en pos de progresar indefinidamente. El ser humano, de esta manera, se concibe como un producto del medio social y de las instituciones. Esta concepción acerca del progreso permite comprender cuál es el sentido de la historia para la Ilustración.

La historia se comprende como el lento camino del hombre hacia la perfección. Camino en el que ha tenido que superarse una serie de obstáculos: la superstición, la intolerancia, la ignorancia, la guerra, el absolutismo; considerándose estos factores los que continuamente entorpecen el advenimiento del progreso. ${ }^{6}$ Así se llega a una concepción discontinua del devenir histórico, por la existencia de épocas oscuras e irracionales, como hiatos que interrumpen la marcha del progreso.

Por otra parte, no hay que olvidar que al desarrollo y triunfo de las ideas de la Ilustración se debe la derrota del poder medieval. En virtud de este pasado surge dicha visión discontinua de la historia, y se juzga el pasado inmediatamente en forma anacrónica.

La Edad Media significaba una época de tinieblas que llevaba consigo una cantidad de errores. Voltaire ve en ella un baluarte de irracionalidad y superstición, que es preciso borrar y no sólo en esa época sino en la historia misma. ${ }^{7}$

Voltaire, con su habitual ironía, denuncia no sólo las fábulas aceptadas todavía por los hombres de su tiempo, sino también el gusto por las anécdotas históricas, por las "bagatelas ilustres" que constituyen los relatos de la corte, tan poco interesantes como las murmuraciones de

5 Ibid., p. 202.

${ }^{6}$ Gustavo Escobar Valenzuela, La Ilustración en la filosofia latinoamericana, México, Trillas, 1980, p. 15.

7 Ibid., p. 16. 
las pequeñas ciudades a las que son aficionadas las mujeres de provincia. Finalmente, según dice, condena también, después de haber leído cuatro mil descripciones de batallas y algunos centenares de tratados, la historia diplomática y militar pura: "En el fondo me quedaba igual que antes [...] Sólo me enteraba de acontecimientos" [...] en resumen: se trata de cambiar la materia habitual y la problemática de la historia." " Desde otra perspectiva intenta cambiar las curiosidades del historiador en su temática y forma de objetivizar el pasado.

Para los ilustrados la visión de la historia tiene un aspecto positivo: es una marcha progresiva; y muestra de hecho un aspecto negativo: el rechazo del pasado inmediato. ${ }^{9}$ Es precisamente ésta, la forma de entender la historia de algunos pensadores hispanoamericanos del siglo XIX. La vuelta al origen, a la génesis del hombre y de la naturaleza para ver a la humanidad en su progreso será, como hemos visto, uno de los puntos que articula la visión de la historia en ese momento conocido como la Ilustración. Ésta será para José del Valle la base desde donde construye los presupuestos de su filosofía de la historia.

Valle expresa que la historia es: "una de las secciones del sistema de conocimientos humanos que ha tenido mayor número de panegiristas"10 en el sentido que muchos se han referido a ella a lo largo de los siglos, sin pasar desapercibida por los pensadores de todos los tiempos: "Es la preceptora de los hombres, decía el orador de Roma, su guía y su luz. Ella nos da (reunida en un libro) dice Dión la experiencia de los siglos". ${ }^{11}$

Según Valle, la historia se constituye a sí misma en la medida que presenta "hechos", estos hechos pueden interpretarse a la manera durkhiana de los hechos sociales como cosas por su apego con la realidad, entendida esta realidad como la verdad: "Las teorías, escriben los

8 Pierre Villar, Iniciación al vocabulario del análisis histórico, Barcelona, Crítica, 1982, p. 37.

9 Escobar Valenzuela, op. cit., p. 16.

10 José Cecilio del Valle, "Historia", 18 Conejo. Boletín literario de la editorial universitaria, núm. 19, Tegucigalpa, 19 de agosto, 1989, p. 4.

11 Loc. cit. 
enemigos de ellas, son la peste destructora de los pueblos. No se encuentra la verdad en las abstracciones, sistemas o delirios del filósofo. Los hechos son los que se manifiestan, y la historia es la que nos presenta hechos". 12

Por lo tanto el quehacer científico y filosófico se define por las capacidades a las que invita el pensador: "observad los fenómenos, mirad los hechos, conoced sus relaciones". ${ }^{13}$ Con lo cual el saber histórico se define por su sistematicidad de observación y comprensión del sentido de los fenómenos, en tanto que: "el hombre que estudia las ciencias de las sociedades aprende en una escuela práctica, lo que podría enseñarle la teoría más útil". ${ }^{14}$

La historia es entonces, para Valle, un lenguaje narrativo que trasciende toda posibilidad de alteración o discontinuidad en la búsqueda de la objetividad de comprensión de los hechos históricos:

La historia no es una teoría concebida de lejos de la naturaleza, no es un gabinete de abstracciones. Es la observación juiciosa de lo que sucede en la realidad, la narración imparcial de lo que ha sucedido efectivamente. No expresa lo que imagina un solitario retirado del mundo de los fenómenos. Manifiesta lo que ha sido, descubre el desarrollo de los seres, es la expresión de la verdad. ${ }^{15}$

En efecto, la teoría de la historia que propone Valle no es la exposición de tesis abstractas sobre los conceptos de historia e historiografía, sino siguiendo al mismo Voltaire, el relato más o menos pormenorizado a partir de un hilo conductor filosófico de la sucesión de civilizaciones que ha conocido la humanidad con relación a su medio ambiente. Dentro de su lógica sistémica de pensamiento, la realidad histórica es inseparable de la naturaleza, considera que ésta la vivifica; sin ella, la

2 Loc. cit.

13 Loc. cit.

14 José Cecilio del Valle, Obra escogida, introd., selec. y pról. de J. M. García Laguardia, Caracas, Biblioteca Ayacucho, 1982, p. 345.

15 Valle, "Historia"... 
tierra sería "un bosque de malezas en unos puntos y un desierto sin vida en otros", ${ }^{16}$ por lo tanto, en toda investigación se vuelve necesario que:

Estudiemos la materia bruta que es lo más sencillo de la naturaleza; subamos después a la materia vegetal que presenta fenómenos más difíciles; trepemos sucesivamente a la materia animal que aparece más complicada en funciones, ascendamos al hombre, que es el ser más grande de la tierra [...] En lo político como en lo físico no se hace de repente. Todo se va formando lentamente. Las peras que hermosean una mesa no son frutos sazonados en un día. Sudó el labrador, limpiando, arando, preparando y sembrando la tierra, comenzaron a desenvolverse los gérmenes tiernos de las plantas, fueron creciendo poco a poco [...] El mundo político está sin duda sometido a leyes constantes como el físico. Mucho tiempo ha que leo y releo la historia, sólo para ir descubriendo esas leyes. ${ }^{17}$

Al establecer esta relación de las leyes de la naturaleza con las realidades políticas, Valle comprende que para estudiar al ser humano como sujeto de la historia no se le puede separar de su contexto vital. La relación cultura/naturaleza es central en su planteamiento: la geografía, geología, ecología, etc. Hace falta establecer una integración e interrelación del hombre y la cultura con la naturaleza, recordando que el ser humano es el ser más grande de la tierra o el centro de la vida por su capacidad y conciencia de conocerse a sí mismo. Siempre y cuando descubra su posición en el mundo. La historia desempeña un papel determinante para que el hombre descubra también las leyes que lo rigen en medio de una naturaleza y una sociedad en la cual tiene que vivir y a la cual debe transformar. De este modo el ser humano se constituye en el sujeto de la historia.

Este entorno físico y su relación con la cultura/naturaleza es condición para que el ser humano advierta su horizonte de sentido en la historia, ya que este ambiente natural en que se desenvuelven las personas cambia continuamente. La historia guarda entonces una relación direc-

16 Citado por Ramón Oquelí, "La historia no se cansa"..., p. 6.

17 Loc. cit. 
ta con el momento de construir una sociedad, por lo tanto hay que entender la sociedad, las formas de vida, el tipo de relaciones que se establecen en los diferentes periodos, para medir el avance de esa sociedad, de un pueblo o nación; es esencial que se conozca sus condiciones económicas y políticas en sus diferentes etapas, para tener una visión total en este sentido, la historia:

Es un curso de ciencias morales, políticas y económicas, presenta el cuadro del país donde se han unido los hombres para vivir en una sociedad; indica su clima, aguas, vientos, producciones, etc., descubre el origen primitivo del estado, manifiesta las formas de gobierno que han adoptado sucesivamente, las leyes que se han dictado o recibido, y las influencias de esos sistemas físicos y políticos en la moralidad, ilustración y riqueza de los pueblos; desarrolla la cadena de sucesos derivados unos de otros y ligados entre sí todos, los progresos o retrocesos, las causas que dan impulso a los primeros o producen los segundos, los tiempos de luz, y los días de tinieblas, las épocas de vida y los periodos de muerte. La historia presenta simultáneamente la teoría y la práctica. Es la política en acción, la crisología obrada, la ciencia moral demostrando sus principios con hechos. ${ }^{18}$

La historia es entonces, para Valle, el escenario en el cual interfieren procesualmente todos los elementos de la sociedad. La tarea del historiador consiste en descubrir la verdad o esencia de esos procesos, con "principios y hechos" donde se elimina toda interpretación providencialista de la historia, al concebirla como un proceso o como "la cadena de sucesos derivados unos de otros, pero ligados entre sí todos [...]."

Las causas que dan impulso a la idea de un Dios que conduce la historia en este autor, desaparecen y no se puede olvidar que esto también sucede con los pensadores ilustrados europeos y quizá Voltaire sea el más representativo. El hecho que la historia se haya situado bajo la acción de una fuerza divina y providencial que cumple sus elevados fines a pesar de la resistencia de los hombres. Voltaire no habla jamás de se-

${ }^{18}$ Ibid., p. 15. 
mejante dirección providencial, quizá reproduce, de alguna manera, la actitud y la orientación realista de un Tucídides. ${ }^{19}$

En Voltaire la naturaleza humana (que puede ser pulida) vive entregada a sí misma en el medio ambiente: "sus energías y pasiones se ven unas veces estimuladas y otras veces entorpecidas por las fuerzas naturales cuyo juego determina el curso de la historia, que es el encargado de decir lo que tiene que suceder". ${ }^{20}$ Así es posible entender en Valle esta estrecha relación entre la naturaleza y lo humano, demostrando una inmanencia de lo humano. Su destino está dado por estas fuerzas, entonces, por esto es necesario conocer las leyes naturales que determinan los cambios del hombre respecto de la naturaleza.

Al igual que Voltaire, Valle sigue en alguna medida a Tucídides. Como buen lector de la historia antigua y de la de los ilustrados europeos, le será fácil continuar con esta línea de reflexión histórica.

Tucídides, autor de la Historia de la guerra del Peloponeso antes de escribirla había participado en ella. Cuando estalló el conflicto entre Atenas y Esparta, conocida como la guerra Peloponesa, Tucídides cumplió con los deberes que le imponía la ciudadanía y debió hacerlo satisfactoriamente, ya que en el año 424 mereció que se le confiara el mando de una flota que debía prestar su ayuda a la colonia ateniense de Antípolis, sitiada por el espartano Brasidas. Tucídides falló en su intento, lo cual determinó que Antípolis cayera en manos de los espartanos, y el jefe de la expedición naval, para purgar su culpa, fue desterrado de Atenas durante 20 años, los mismos que pasó en Trucia. El destierro le dio la oportunidad de analizar con rigor y objetividad el curso de la conflagración. De ahí que Tucídides haya escrito: "estando (en Trucia) en relación con ambos bandos, con los peloponesios aún más que con los atenienses, a causa de mi exilio, me hallé de ese modo en condiciones de observar serenamente el curso de los acontecimientos". 21

19 Cfr. Enrique González Rojo, Teoría científica de la historia, México, Diógenes, 1977, p. 194.

20 David Strauss, citado por González Rojo, op. cit., p. 194.

${ }^{21}$ Citado en ibid., p. 194. 
El propósito que persigue en esta obra, que no logró terminar, es el de ser cabalmente sereno, imparcial, objetivo. Por eso decía: "en cuanto a las cosas que se hicieron durante la guerra, no he querido escribir lo que oí decir a todos, aunque me pareciesen verdaderas; solamente lo que vi por mis propios ojos. Y supe. Y entendí por medio de personas dignas de fe, que tenían verdadera noticia y conocimiento de ellas". ${ }^{22} \mathrm{Su}$ preocupación es entonces alcanzar siempre un nivel de verificación que pueda asegurarle a su obra la perduración sin necesidad de enmendarla esencialmente por nuevas comprobaciones. Para el ateniense Tucídides la historia real y verdadera es la que ha sido escrita por personas que han sido testigos o actores y siempre y cuando el historiador sea objetivo, que se inhiba al hombre a favor del científico.

En Valle se advierte esta influencia, en cuanto la historia se interprete objetivamente y en la medida que sea escrita por alguien que ha sido testigo de ella:

Franquee usted a un sujeto todas las gacetas, todas las correspondencias oficiales, todos los archivos de un país; no será buen historiador sino ha sido espectador de los sucesos. Es infinita la distancia entre lo que sucede y lo que escribe. Yo no daré mis confianzas sino a los historiadores imparciales, antiguos o modernos, que hayan sido testigos de los hechos y poseído talentos penetrantes. ${ }^{23}$

Pero esta concepción tiene para él una preocupación de fondo, la historia es sensible a los errores y esto es perjudicial siempre para los hombres del presente como del futuro. Por eso plantea:

No publiquemos errores ni hagamos cálculos falsos. El error es siempre dañoso y comunicado a una generación continúa haciendo mal a las siguientes. Todavía sufrimos las consecuencias de lo publicado en los slglos precedentes, todavía lloramos algunas teorías que dio a la luz el XVII. Di-

22 Loc. cit.

23 José Cecilio del Valle, Antología, introd., selecc. y notas de Ramón Oquelí, Tegucigalpa, Universitaria, 1981, p. 319. Cursivas mías. 
fundamos conocimientos útiles, conocimientos que jamás causen perjuicio y hagan siempre bien, conocimientos que influyan en la riqueza de las familias y contribuyan a la prosperidad de las naciones. ${ }^{24}$

\section{La historia como progreso}

Al profundizar en la teoría del saber histórico en José del Valle se observa que la idea del progreso ligada a la historia también encuentra acogida. Esto significa asumir la idea de que la humanidad avanza gradualmente hacia un estado de perfección y racionalidad. El ser humano es un ser perfectible, capaz de progresar indefinidamente. Comparte desde luego la idea de los ilustrados, que la historia es el lento camino del hombre hacia la perfección, en el que se supera toda una serie de obstáculos, pero, sobre todo, se establecen relaciones del pasado con el presente:

En la historia recibe el siglo presente las experiencias de los siglos pasados, se enlazan los unos con el otro, es uno el tiempo, no hay interrupción en la serie dilatada de los años, los que preceden dan luces a los que siguen, el hombre ve penetrado de gozo esta atmósfera de luz, adquiere conocimientos que no podría darle una vida tan breve como la suya, dilatada la esfera de sus conocimientos, aprende a abrazar grandes relaciones y recorre espacios inmensos; el estadista observa cómo han ido naciendo los pueblos, cómo han crecido y de qué manera han muerto, conoce los resortes que han dado impulso a sus progresos, y los obstáculos que los han impedido o retrasado, descubre las causas de su vida y de su muerte. ${ }^{25}$

Y en este progreso también el pensamiento avanza sobre la base de su pasado, siempre y cuando los hombres rescaten e interpreten los conocimientos anteriores:

La marcha de los siglos ha sido lo que era natural que fuese. Los primeros del renacimiento de las letras, buscaron entre las ruinas que dejaron los conquistadores del norte, los pensamientos de los sabios de Grecia y Roma;

${ }^{24}$ Ibid., p. 320.

25 Valle, "Historia"... 
los siguientes interpretaron, comentaron y hermosearon, aumentaron y aplicaron a las necesidades del hombre y prosperidad de los pueblos; el presente los multiplica y propaga por el mundo, los circula por las naciones y los difunde por todas partes. ${ }^{26}$

Sin embargo, esta visión del progreso no es un entendimiento evolutivo per se. A pesar de ver y establecer relaciones entre un siglo y otro, un acontecimiento y otro, Valle tiene una concepción discontinúa de la historia, por la existencia de épocas oscuras e irracionales como hiatos que interrumpen la marcha del progreso. Y en este sentido observa su pasado inmediato en forma anacrónica. Para él la época colonial latinoamericana significaba un periodo de oscuridad, de tinieblas, la cual había que recuperar: "La pobreza, la miseria, la ignorancia, el embrutecimiento, debían ser efectos precisos de un sistema tan funesto. No había esperanza de que a una noche tan oscura siguiese al menos un crepúsculo de media luz" ${ }^{27}$ por lo tanto es preciso recordar y trabajar: "en el cuadro de los siglos o años de ignominia y desgracias; pero vuelva llena de gozo y alegría a las épocas de honor y gloria". ${ }^{28}$

En este sentido llega a periodizar la historia de la humanidad en tres estados: el de la ignorancia, el del error, y el de la ilustración: "Recorriendo la historia de los pueblos antiguos y volviendo la vista a los modernos, se observa que todos tienen uno de tres estados: el de la ignorancia, el del error, y el de la ilustración", ${ }^{29}$ se observa entonces una lectura a partir de Voltaire de la historia, quien enjuicia el pasado histórico a través de los principios cardinales de la Revolución francesa. Por Igualdad, la formal de todos los "ciudadanos" ante la ley. Por Fraternidad, la cualidad que se desprende del hecho de que todos los hombres están hermanados por el carácter racional de la naturaleza humana; y por la Libertad entendía la supresión de los privilegios feudales y del régimen de servidumbre. Todos aquellos periodos históricos en los que

\footnotetext{
26 Loc. cit.

27 Valle, Obra escogida..., p. 351

28 Valle, Antología..., p. 314.

29 Loc. cit.
} 
no hay libertad, igualdad y fraternidad son irracionales. La edad media es el reinado oscurantista de lo irracional. ${ }^{30}$

Este es el marco que desarrolla Valle para percibir y observar la historia, épocas de oscuridad y luz. Así en una diáfana lectura de Voltaire, escribe Valle:

Los amigos de la ilustración contemplan la marcha de las artes y ciencias desde las primeras sensaciones de los salvajes hasta los inventos más sublimes del Genio; descubren lo que da impulso feliz a los movimientos, lo que les hace progresar o retroceder, lo que hizo Cicerón y Newton, lo que hizo tenebrosa las edades de los vándalos, godos, etc. ${ }^{31}$

Unido a lo anterior Valle observa que en la historia de toda nación, los primeros tiempos se caracterizan por su desconocimiento y representan una etapa oscura, por carecer de elementos que representen luces: "El primer periodo de la historia de una nación es siempre oscuro o muy poco luminoso. Los pueblos son como los hombres, no conservan de su infancia más que una memoria confusa, que si recuerdan algunos hechos, no tienen presentes otros, ni ven con claridad los demás". ${ }^{32}$ Sin embargo, es en este marco donde la historia adquiere toda su importancia, a pesar de estas etapas difíciles poco conocidas, pero que han marcado el futuro de las naciones, la historia cumple su función de esclarecer el pasado para vivir un mejor presente, enseñando el arte de vivir:

[...] publicando la verdad en toda su pureza, la historia no engendra odios ni venganzas. No es autora de discordias ni de guerras intestinas. Es maestra experimentada de prudencia, y sus lecciones, derivadas de los siglos, no son de mal sino de bien. Se place en los odios políticos que tienen por objeto el espíritu de la conquista, el de intervención en los negocios de otra nación, el de dominación absoluta, pero carga de horror los odios personales unos contra otros individuos que deben penetrarse de un mismo espíritu. Enseña a ser previsores, cautos y prudentes, pero quiere que todos se unan en derredor de la patria, que todos sean ciudadanos, amigos colaboradores

\footnotetext{
${ }^{30}$ Cfr. González Rojo, op. cit., p. 314.

31 Valle, Antología..., p. 314.

32 Loc. cit.
} 
en beneficio de la madre común, penetrados de aquella rivalidad noble de talento y mérito, que ha sido siempre la creadora de los grandes hombres. ${ }^{33}$

De aquí se desprende, de acuerdo con Valle, lo trascendental del conocimiento histórico. Esto es, que permite ver con más claridad la necesidad de una nueva forma de gobernar, de llevar las luces de la educación a las mayorías. Esto se logrará siempre y cuando todo gobernante conozca con profundidad la historia de su nación: "Se considera su estado presente, y no se ha hecho estudio de los anteriores por donde ha pasado, se ve su superficie y no se penetra más allá, se mira su fisonomía exterior, y no se tiene idea de su alma, [... así una nación] ¿podrá ser bien gobernada?”. ${ }^{4}$

El principio de causalidad histórica de los fenómenos es siempre su meta superior, lo aparente de las cosas para tener una verdadera comprensión de la realidad social e histórica, a fin de saber gobernar y unificar al pueblo. Por esto Valle reiteradamente observa una nación en su dimensión histórica y esto es lo que sella su pensamiento. El presente no se comprende sin su pasado, ambos son inseparables. En ese sentido, para este autor, la historia cumple una función "totalizadora", que permite conocer en su esencia el estado de una nación, un pueblo. Por esto nos dice: "El que no observa a un pueblo más que en su actual posición, es como el que no ve a un hombre más que en un acto solo de su vida; para conocer a un hombre es preciso verle en todos los periodos; y para conocer a un pueblo es necesario observarle en todas las épocas de su historia". ${ }^{35}$

\section{EL SUSTRATO POSITIVISTA: RAMÓN ROSA}

En el pensamiento histórico de Ramón Rosa (1848-1893) no se advierte claramente una influencia hegemónica de tal o cual corriente de conocimiento, sino más bien una suerte de sustrato teórico que, de alguna

\footnotetext{
33 Loc. cit.

34 Loc. cit.

35 Loc. cit.
} 
manera, refleja una moda de pensamiento y una manera de actuar guiadas por el positivismo y por una suerte de pensamiento ilustrado. Este es el trasfondo o el sustrato del que emerge su manera de pensar lo social, lo político y lo económico. Sin duda alguna, el pensamiento de Ramón Rosa muestra la síntesis de un liberalismo clásico, de manera similar a lo efectuado por los franceses del siglo XVIII, que situaron en un lugar privilegiado el estado de la Razón con la abolición del régimen feudal y de la vieja aristocracia. ${ }^{36}$

Del mismo modo se reconocen en las ideas, en el flujo positivista de esta generación, las ideas de Comte y Litrre, transmitidas por el chileno José Victoriano Lastarría (1810-1884) y por los argentinos Domingo Faustino Sarmiento (1811-1888) y Juan Bautista Alberdi (1810- 1884). Rosa se acerca al positivismo no directamente en la obra de Comte sino por medio de sus principales difusores en América Latina, como los antes citados.

\section{El positivismo: historia y progreso}

Ramón Rosa, como varios de los intelectuales de su momento vieron en el positivismo un camino para superar la realidad de su tiempo, saturada de vicios coloniales y de superstición religiosa que daban carácter débil y estéril a las ideas y a las formas de organización social y política existentes. Sin embargo, como ha explicado Roberto Castillo, es saludable recordar que el positivismo de los países latinoamericanos, aunque con la influencia europea, tiene rasgos propios, uniéndose la concepción teórica del positivismo a la idea política liberal, que buscaba realizar las transformaciones materiales, políticas e ideológicas que permitirían a las nuevas naciones fortalecerse, tanto interna como externamente. ${ }^{37}$

36 Gustavo Zelaya, El legado de la reforma liberal en Honduras, Tegucigalpa, Honduras, Guagmuras, 1996, p. 29.

37 Roberto Castillo, Filosofia y pensamiento hondureño, Tegucigalpa, Editorial Universitaria, 1992, p. 20. 
Augusto Comte, fundador del positivismo, no duda en señalar que esta filosofía no es más que una alternativa que responde a las necesidades de su tiempo, siendo un rasgo característico del espíritu positivo el estar con el espíritu de su tiempo, de su siglo, y lo que le da vitalidad histórica a ese siglo es el afán compuesto por el orden y progreso. El orden como principio, el progreso como fin. ${ }^{38}$ Para un autor como Habermas:

El positivismo significa el final de la teoría del conocimiento. En lugar de esta última, aparece una teoría de la ciencia. Si la problemática lógicatrascendental acerca de las condiciones del conocimiento posible aspiraba también a la explicación del sentido del conocimiento en general, el positivismo, en cambio, elimina esta cuestión, que para él ha perdido sentido gracias a la existencia de las ciencias modernas. El conocimiento se encuentra implícitamente definido por la propia realidad de las ciencias. Por esto, la cuestión trascendental acerca de las condiciones de un conocimiento posible, únicamente se puede entender bajo la forma de una investigación metodológica sobre las reglas de constitución y de comprobación de las teorías científicas. ${ }^{39}$

No es un resultado contingente que los reformadores del siglo XIX se hayan identificado con el positivismo, constituyendo éste el movimiento intelectual dominante en la segunda mitad del siglo XIX. Esta filosofía se expandió vertiginosamente en Inglaterra, Alemania, y después en América, adquiriendo caracteres muy propios y diferentes respecto a los que les imprimió su fundador. ${ }^{40}$

La teoría de la historia positivista busca descubrir las leyes del desarrollo social, al pretender elevarse por encima del materialismo y el idealismo y no ser ni uno ni otro. Al buscar la existencia de leyes en la sociedad, y por lo tanto al intentar establecer un método que estudie a la socie-

38 C. Perdomo, Pensamiento positivista liberal de Ramón Rosa, Tegucigalpa [s. e.], 1994, p. 4.

39 J. Habermas, Conocimiento e interés, trad. de M. Jiménez, J. F. Ivars y L. M. Santos, Madrid, Taurus, 1982, p. 75.

40 Loc. cit. 
dad, se inclina por la imitación mecánica de las ciencias naturales. Así el método histórico positivista es el inductivo, para ir hacia la elaboración teórica, resultando así un claro empirismo. ${ }^{41}$

Los enfoques de carácter histórico de Ramón Rosa, Antonio R. Vallejo o Rómulo Durón y otros historiadores de la época centrarán su reflexión en la teoría de los tres estadios de Comte (edad religiosa, metafísica y positiva $)^{42}$ y a partir de ahí construirán el concepto límite del pensamiento histórico de este periodo que es el del progreso.

El desarrollo histórico de las sociedades se entiende como progreso, lo que necesariamente implicaba desterrar los vestigios coloniales y potenciar el papel de la educación pública, laica y universal con carácter obligatorio, que sería el factor decisivo en el anhelo de modernización, entendido este término de acuerdo con Argueta, como un "marchar al lado" del mundo industrial europeo y norteamericano, anhelo ya claramente percibido en los escritos de José Cecilio del Valle. Además el desarrollo histórico implicaba la apertura infraestructural del país como requisito indispensable para establecer un mercado nacional, la consolidación de sectores vinculados al aparato estatal y a las actividades agropecuarias y mineras orientadas a fortalecer una economía exportadora. ${ }^{43}$

No se puede olvidar que la idea de progreso es propia del mundo moderno, alimentada por los avances de la ciencia, la técnica y las ansias emancipadoras de la humanidad. Consiste en afirmar que la humanidad partió de una situación inicial de barbarie y ha venido mejorando sin cesar desde entonces como en un contínuum hacia el futuro. Así pues, no entraña sólo una revisión del pasado, sino también una profecía sobre el futuro. Como decía Lincoln Steffens, "he visto el futuro, y os aseguro que funciona". ${ }^{4}$

${ }^{41}$ Cfr. Miguel Gallo, ¿Qué es la historia?, México, Quinto Sol, 1989, pp. 29-30.

42 Cfr. Ramón Rosa, "Discurso de apertura de la Universidad", en Valle, Obra escogida..., pp. 249-280 y Zúñiga, op. cit.

43 Mario Argueta Dávila, Tendencias e investigaciones recientes de la sociología hondureña: un ensayo bibliográfico, Tegucigalpa, Editorial Universitaria, 1981, p. 12.

${ }^{44}$ Cfr. Robert Nisbet, Historia de la idea de progreso, Barcelona, Gedisa, 1981, p. 420 . 
Esta noción de progreso tiene un origen no anterior al siglo XVII. Hasta ese momento era frecuente interpretar la historia más bien en clave de decadencia, a partir de una situación inicial de plenitud. De esta manera, con la noción de progreso no sólo se afirma que la humanidad ha avanzado gradualmente durante el pasado, sino que sostiene también que seguirá avanzando indefinidamente en el futuro, y además de forma necesaria. Kant llegó a decir que se necesitaría un nuevo Kepler, un nuevo Newton, que hallase la ley del movimiento de la civilización. ${ }^{45}$

Para Ramón Rosa y varios de los pensadores hondureños de este periodo, como muy bien lo ha estudiado Gustavo Zelaya, ${ }^{46}$ el progreso encontraría su sentido en la historia, siempre que mejorara la vida humana por medio de la razón y sus productos más acabados. Ello provocaría una disminución de la ignorancia y un incremento sustancial de la felicidad. Ramón Rosa lo manifestó de la siguiente forma:

Vivimos abrumados por una naturaleza tan rica y grandiosa como áspera y salvaje. Para realizar el progreso, que es nuestro bien, tenemos que luchar las materiales dificultades que nos opone; para esa ruda lucha necesitamos fuerza y ardimiento, y esos elementos de poder sólo pueden dárnoslos las ciencias físicas y matemáticas. ${ }^{47}$

Se busca establecer una teoría de la historia cuyo elemento determinante es la naturaleza, y el hombre visto como un ser objetivo, sensible, que se constituye y desarrolla a través de su propia práctica, pero sobre la base de un repertorio de relaciones activas y pasivas con la naturaleza y la sociedad. Esa determinación es la que define al hombre, lo obliga, se le impone necesariamente como condición de su existencia; pero frente a esta determinación encontraron más importante la razón y las nociones que produjera, como elementos primordiales del progreso.

${ }^{45}$ Cfr. J. González-Carvajal, Ideas y creencias del hombre actual, España, Sal Térrea, 1988, p. 116.

46 Para este apartado remito directamente al trabajo de Gustavo Zelaya, op. cit., pp. 29-45.

${ }^{47}$ Rosa, op. cit., p. 280. 
Se desentendieron, por tanto, de lo fundamental en cuanto a la formulación de interpretaciones históricas. Es decir, cualquier manera de proponer la historia siempre tendrá como respuesta humana esa determinación material del mundo que es la naturaleza. Por ello, el hombre dispone y ha dispuesto de la posibilidad de responder tecnológicamente a los retos de esa tendencia predominante; tiene, entonces, la oportunidad de controlar y dominar el mundo exterior por medio de los instrumentos que le proporciona la ciencia, la técnica y, por ende, la educación. Esta era la finalidad del progreso: el conocimiento y la felicidad del hombre, concebida la meta como el producto de un proceso natural ilimitado, que no admite saltos ni posibilidad alguna de experimentar regresiones.

Otra característica de esta concepción de la historia es el significado evolutivo y gradual del paso de una etapa a otra, como parte de un plan ordenador y natural, en donde el papel central lo desempeña la razón humana.

La noción del progreso recogió las inspiraciones de superar las viejas limitaciones de la vida material y espiritual y reflejó, igualmente, la intención de implantar otras formas que sirvieran para salir del atraso general en que se encontraba el país. Existía, pues, la necesidad de poner a disposición de toda la sociedad los más elementales instrumentos de desarrollo que estimularan en los hondureños las posibilidades para desarrollarse como tales, es decir, para realizarse humanamente. Esa visión optimista del progreso consideraba que la reforma política, económica y social era una especie de luz que se haría más intensa gracias a la conciencia que los hondureños forjaran al ser favorecidos con el nuevo sistema educativo, con la nueva legislación y con la industria. Al respecto, Rosa definió el momento de la siguiente manera: "La reforma no es una promesa; es la realización progresiva de los bienes sociales. El estudio de la historia que nos enseña a juzgar los hombres y los acontecimientos, cada día nos evidencia más y más el curso natural e indefectible de las revoluciones político-sociales [...]" ${ }^{48}$

48 Loc. cit. 
Para Rosa claramente el positivismo fue, más que una doctrina filosófica, un modo de instalación de las nuevas sociedades, una forma de ingreso posible a la civilización a través de la alternativa de ruptura con el pasado colonial, mediante un nuevo mito unificador de todos los sectores políticos. Es un modo de pensar y de proceder, es decir, una forma de pararse frente a la vida y de interpretar el todo.

\section{La utilidad del conocimiento histórico}

La teoría de la historia y el proyecto social de Rosa se corresponden muy bien con el contexto social en que surgen. Una sociedad que viene de la anarquía, de la guerra, la inestabilidad, el regionalismo y la fragmentación requiere de una adecuada comprensión de su historia. Honduras se constituirá en un Estado inestable de acuerdo con Oquelí, y fragmentado, sin mayor conciencia de vida republicana y de sentimiento nacional. De ahí la necesidad de volver a los inicios de la vida republicana y los repetidos alegatos por la emancipación. En Ramón Rosa la Independencia es el hecho histórico más importante en la historia de Honduras y de Centroamérica. ${ }^{49}$

Dentro del proyecto liberal de construcción del Estado-nación de Rosa, se busca una teoría capaz de ofrecer luces sobre la historia caracterizada por las cruentas luchas que prosiguieron al proyecto federal en Centroamérica desde 1842 a 1876. En este sentido la teoría de la historia positivista permitía la búsqueda de legitimación de la República independiente y la aproximación a una "nueva era". Este influjo ideológico, como la búsqueda de legitimación de la Independencia y la formación de un Estado-nación, pone de manifiesto que para los reformadores liberales la utilidad de la historia es alimentar una historia de "bronce", utilizando la expresión del historiador mexicano Luis González. Historia que se define como pragmática por excelencia, que se ocupa de hombres de

49 Cfr. Rosa, "Consideraciones generales sobre la independencia de Centro América" y

"La independencia desvirtuada", en Obra escogida... 
estatura extraordinaria (gobernantes, santos, sabios y caudillos): presenta los medios desligados de sus causas, como simples momentos dignos de imitación. ${ }^{50} \mathrm{Al}$ ser esta la historia preferida por los gobiernos, es una forma de emplear la historia que continúa hasta el presente.

Así se comienza a construir la idea de héroes de la Independencia hondureña y emergen con todo su significado los nombres y las figuras de Francisco Morazán, Dionisio de Herrera, José Trinidad Reyes, como baluartes del proceso de construcción del Estado y la Nación hondureña. De aquí que Morazán se haya convertido en el símbolo de la nación hondureña y en el héroe nacional por antonomasia y se exalte su figura guerrera y militar. Este discurso historiográfico se encuentra dominado por un fuerte sentido anticolonial, más que español, que se expresa no sólo en la hostilidad manifiesta contra todo lo que representaba el periodo colonial, sino que es una revisión de todo el discurso patriótico. No sin razón cuando a Antonio Ramón Vallejo se le asigna escribir una historia nacional, ésta arranca desde1821 y no hace referencia al periodo colonial. Este último será definido e interpretado como una etapa de oscurantismo, como elemento histórico justificativo del Estado nacional y una etapa que había que superar:

Hoy he despertado de esos sueños aterradores que me sumían en la pavorosa noche del pasado colonial; y es porque nuestras nuevas instituciones ya no organizan nuestras familias bajo un sistema romano-feudal; ya no reconocen delitos imaginarios, inventados por la ignorancia de la Edad Media; ya no previenen la aplicación de penas bárbaras o arbitrarias; ya no restringen la explotación de nuestras minas repeliendo al inmigrante, al extranjero; ya no coartan la libertad de comercio, con restricciones atentatorias a las garantías del capital y del crédito. Señores: cuando los monárquicos ven morir a su rey, exclaman: '¡El rey ha muerto, viva el rey!', y yo, como republicano, hoy que el trueno del cañón saludó la promulgación de nuestros Códigos, inspirados en la justicia y en la ciencia moderna, no puedo menos de exclamar: ¡La colonia ha muerto $¡ . . . ~ ¡$ Viva la República! ${ }^{51}$

${ }^{50}$ Citado por Oquelí, Los hondureños y las ideas..., p. 22.

${ }^{51}$ Rosa, Obra escogida..., p. 334. 
Otro elemento característico de la vinculación entre la teoría de la historia y el proyecto social es su relación con el poder público, lo que lo convierte de una u otra manera en un discurso "oficial", hasta cierto punto ideológico y por lo tanto aparece como gran protagonista de la historia el gobierno y el Estado. Es el Estado el que crea la infraestructura historiográfica y el que financia la preparación y publicación de los textos históricos.

\section{La memoria histórica}

Ramón Rosa definió el conocimiento histórico como la memoria de una nación, es decir como lo que él muy bien llama "conciencia del pasado":

Suprimid los archivos, y los pueblos carecerían de la conciencia del pasado. A la manera que los individuos que, por una desgracia o perturbación pierden la vida de los recuerdos; los pueblos sin archivos pierden el recuerdo de sus trabajos, de sus esfuerzos por el bien, de sus ideas, de sus actos, de sus triunfos; de sus dolores, de sus desalientos e infortunios; de sus propósitos, de sus aspiraciones, de sus ideales; y en suma de las grandes enseñanzas que lega siempre el pasado, recogido en el archivo y resplandeciente en las páginas de la historia. ${ }^{52}$

El archivo es para Rosa un elemento de la modernidad y el progreso, es el reflejo de la historicidad de una nación, es la definición de su identidad. Por ello "un pueblo sin archivo, sin historia, sin tradiciones, no puede tener un carácter que lo distinga, que lo haga representar un papel honroso en las magníficas evoluciones del progreso". ${ }^{53}$ La creación del Archivo, según Rosa, es el paso para fundar no sólo una nueva historiografía hondureña, sino los estudios históricos como tales desde una perspectiva científica y documentados:

Por fortuna, el imperio del mal no puede ser eterno; y hoy, después de trabajos y esfuerzos sin número, se han reunido los documentos que, des-

${ }^{52}$ Ibid., p. 331.

${ }^{53}$ Loc. cit. 
de los tiempos del coloniaje hasta nuestros días, contienen los preciosos materiales de nuestra historia; y he aquí que, para honra y bien de la patria, se inaugura el Archivo Nacional. ${ }^{54}$

\section{LA APROXIMACIÓN MARXISTA: FILÁNDER DÍAZ CHÁvEZ}

La influencia del marxismo en la teoría de la historia en Honduras es relativamente reciente en su desarrollo. Si bien existe una historiografía marxista como tal, ésta carece de una reflexión teórica con profundidad, tal como puede verse en las perspectivas ilustrada y positivista, que tanto en Valle como en Rosa ocuparon parte de su pensamiento, interesados en la teoría de la historia en función de sus proyectos sociales y políticos.

Ha sido Filánder Díaz Chávez en su valioso ensayo: Sociología de la desintegración regional (1972), quien en mi opinión, ha hecho hasta ahora el mayor esfuerzo por comprender y explicar la constitución o integración social de Honduras; el primero en aproximarse a una teoría de la historia en clave marxista. Ésta es una de las pocas obras escritas en Honduras desde una perspectiva abiertamente marxista, tanto en el uso del lenguaje como en las categorías de análisis. El mismo Díaz Chávez define este libro como un análisis sociológico, pero sobre todo es, "en no menor grado, una doctrina sobre el subdesarrollo del país hondurense del istmo centroamericano".55

Es importante recordar que el materialismo histórico de Marx y Engels nace en un momento caracterizado por una encrucijada histórica, de impulso para continuar la línea más progresista de la Revolución francesa, traicionada en 1830; por una radicalización del pensamiento ilustrado, preservado en la filosofía de Hegel, frente a la reacción historicista; y por una crítica a las formas de explotación introducidas por el capitalismo y potenciadas por la industrialización. ${ }^{56}$

54 Ibid., p. 332.

55 Filánder Díaz Chávez, Sociología de la desintegración regional, Tegucigalpa, Universidad Nacional Autónoma de Honduras, 1972 (Col. Investigación y Teoría, 1), p. 12.

${ }^{56}$ Fontana, op. cit., p. 138. 
Como muy bien ha explicado el mismo Fontana, el materialismo histórico contiene una concepción de la historia que muestra la evolución humana por medio de etapas de progreso, que no son definidas fundamentalmente por el grado de desarrollo de la producción, sino por la naturaleza de las relaciones que se establecen entre los hombres que participan en el proceso productivo: "Cuando se habla [...] de producción — dirá Marx - se habla siempre de la producción en un estadio determinado del desarrollo social de la producción de individuos en sociedad" ${ }^{57}$

El punto de partida de Díaz Chávez para construir una teoría de la historia es el hecho, a su juicio, que la historiografía y la teoría de la historia hondureñas han estado acosadas "por los vicios que el pensamiento empírico entraña. Y si es cierto que siempre ha existido una cronología histórica, donde ésta se toma por historia, en la cual se hallan desterrados los deseos subjetivos del "historiador..." [el resultado ha sido un empirismo]. Por lo tanto, el proyecto de este autor consiste precisamente en "abandonar la concepción empírica de la historia y lanzarse a construir sobre nuevas bases su concepto". ${ }^{58}$ Para Díaz Chávez la historia aparece, especialmente, como efecto de la estructura social, es decir, como un todo complejo, "en el cual, siempre, de modo ineludible, existe un elemento que desempeña el papel dominante y otros que le están subordinados". 59

Para generar conocimiento histórico hay que recurrir al pensamiento científico y superar el conocimiento empírico, es decir, el pensamiento

que rinde tributo a los datos, estadísticas, crónicas y todo fenómeno que le es dado inmediatamente como experiencias de la vida cotidiana, cree poder encontrar la ley de un proceso mediante una lectura inmediata de esos datos y experiencias, que deben entregarle también inmediatamente el secreto de su esencialidad; que el dato habla por sí mismo y sin más necesi-

57 Ibid., p. 149.

58 Filánder Díaz Chávez, La independencia de Centroamérica. Dilatado proceso histórico por la liberación nacional, Tegucigalpa, Federación de Estudiantes Universitarios de Honduras, 1973, p. 7.

59 Ibid., p. 9. 
dad que un oído atento para captar la verdad que nos es dicha; que el documento entrega el misterio de su ciencia solamente con la fuerza de una mirada atenta y culta. ${ }^{60}$

De lo que se trata es de generar un conocimiento que obligue a los datos

a que nos confiesen el secreto que su inmediatez oculta, contraponiéndolos como enemigos, girándolos sobre sí mismos, para descubrir la verdad en el fondo escondido de su torbellino visible; negar la apariencia difundida, reducir el fenómeno a la esencia, el dato a su concepto, encontrar el lazo interior que unifica las esencias reducidas de los datos brutos y empíricos, encontrar el estado necesario y contradictorio de las cosas que los datos señalan, en suma, formular la sistematicidad de las conexiones internas que abarcan la totalidad del objeto estudiado, producir el concepto de su objeto en su estructura interna; he aquí lo que constituye el pensamiento científico.

De esta manera, sostiene Díaz Chávez, de acuerdo con Godelier, que la ciencia "necesita formular explicaciones sin deducir la realidad del concepto y sin reducir la realidad al concepto. De este modo, no reducir es tomar lo real tal como es, en todas sus determinaciones concretas y en su orden específico". ${ }^{61}$

Es a partir de esta visión de la ciencia que este autor comprende el conocimiento histórico como un conocimiento científico que permite superar la visión anterior. La tendencia a entender la historia "como nos es dada en la bella secuencia de fenómenos que se producen en la existencia histórica, ya sea de una sociedad o de un hombre importante, sólo es, sólo puede ser, la sucesión de hechos empíricos inmediatos (datos y acontecimientos), que las 'evidencias' de documentos nos prodigan. Postrarse ante tales evidencias es caer en el empirismo de la historia". ${ }^{2}$

60 Loc. cit.

${ }^{61}$ Maurice Godelier, Racionalidad e irracionalidad en la economía, México, Siglo XXI, 1967, p. 116.

62 Díaz Chávez, La independencia..., p. 7. 
El concepto de historia que Díaz Chávez trabaja es el que se construye no a partir de "la hermosa repetición de los hechos visibles que se suceden como los acontecimientos registrados en los datos de una crónica", sino por el contrario, "el concepto de historia se construye a partir de la estructura articulada de una sociedad determinada, produciendo el conocimiento verdadero, objetivo por lo tanto, de sus diferentes instancias y conexiones orgánicas". ${ }^{63}$

Los efectos de las articulaciones estructurales en su interrelación mutua, sus desplazamientos, su intercambio de papeles son los que producen lo histórico. Son hechos históricos, entonces, entre todos los acontecimientos que se producen en la vida cotidiana de una realidad histórica, los que producen un cambio en las coyunturas estructurales existentes. ${ }^{64}$

Por esto los países subdesarrollados poseen su historia propia, contrariamente a lo que afirman los estudios "desarrollistas" de los ideólogos de las metrópolis, interesados en mantener el subdesarrollo y la dependencia, los cuales señalan que los países subdesarrollados no poseen historia, sino siempre han sido lo que son hoy. Historia propia, regional, capitalista, ya que ha estado y está estrechamente vinculada desde varios siglos a la historia de los países hoy desarrollados, quienes incorporaron "completamente a los países actualmente subdesarrollados al mismo proceso unitario de la historia mundial, que ha originado simultáneamente el presente de algunos países y el actual subdesarrollo de otros". ${ }^{65}$

El hecho de que cada una de estas historias sea relativamente autónoma no puede significar que existan dominios independientes del todo complejo estructurado. El modo y el grado de independencia de una historia sólo pueden concebirse sobre la base de las diferentes relaciones existentes entre las estructuras del todo estructurado, lo cual significa que esa independencia se halla determinada, necesariamente, por el modo y el grado de

63 Loc. cit.

64 De aquí que el conocimiento real de la historia se vincule necesariamente al conocimiento objetivo de la sociedad como un todo estructural articulado.

65 André Gunder Frank, "Desarrollo del subdesarrollo", Suplemento de la Revista Tlatoani, México, 1970, p. 54. 
dependencia de las estructuras del todo global; en el caso de los países dependientes, por la estructura capitalista internacional. ${ }^{66}$

La tesis del autor sobre ciertos aspectos sociales de la realidad hondureña es la siguiente:

Los hombres para producir contraen determinados compromisos o relaciones con el objeto de transformar la naturaleza a través de instrumentos. Esas relaciones de producción se llevan a cabo mediante el lenguaje, que, como se sabe, presupone relaciones sociales. Se puede concluir que la conciencia social, siendo un reflejo del mundo exterior adquirido a través de la producción social, involucra en su estructura las relaciones de producción, y de igual manera éstas se hallan implícitas en el lenguaje. Entonces, si las relaciones de producción cambian, igualmente cambia la conciencia social y el modo de expresarla, el lenguaje. ${ }^{67}$

Los hondureños no han logrado desarrollar un alto grado de conciencia social, es decir, de nacionalidad: "Una notable desintegración nacional, es porque existen fuerzas internas y externas que provocan su desfiguración económica". ${ }^{68}$ La desintegración es la ausencia de una conciencia nacional, cuyo fondo, de acuerdo con el autor, se encuentra en "las seculares raíces de esas viejas estructuras, y que opera como activa agente de desintegración, el hambre igualmente secular de nuestro pueblo" (p. 391).

Las condiciones de pobreza que han caracterizado a Honduras a lo largo de su historia han sido el caldo de cultivo de los problemas sociales y, sobre todo, de la conducta disociadora, así como, en muchos casos, la escasa acción colectiva del pueblo hondureño, que no es otra cosa que la expresión de la inestabilidad política. Para Díaz Chávez, la conducta social disociadora es la tensión que se produce "de la rebeldía a la explotación. En esa pugna contra la explotación encontramos una de las bases para explicar las innumerables revueltas, erróneamente lla-

\footnotetext{
66 Díaz Chávez, La independencia..., p. 7.

${ }^{67}$ Díaz Chávez, Sociología de la..., p. 391.

68 Loc. cit.
} 
madas revoluciones, que en el pasado han paralizado al país, como también la fundamentación del comportamiento anárquico del hondureño en sus relaciones de trabajo". ${ }^{69}$

Esta continua relación hambre-rebeldía tiene como causa un tronco común de idénticos males: "una economía agraria deformada, proveniente del latifundismo feudal heredado de la colonia". ${ }^{70}$ Tanto el colonialismo como el neocolonialismo son para Díaz Chávez negación de la nacionalidad. El neocolonialismo es la variable externa que impide la constitución de un sentimiento común. Pero esta desintegración y ausencia de nacionalidad también tiene como causa una serie de variables internas, que es preciso considerar: "un alto grado de anarquía, pero aún más de la frustración, como expresiones más o menos elaboradas del hambre y la rebeldía a la explotación. Empero, en la frustración se hallan los fundamentos del alcoholismo generalizado, actuando ulteriormente como artificio para fugarse del medio ambiente opresor. Además, en una etapa paralela, la anarquía condiciona la corrupción administrativa" ${ }^{71}$ La anarquía y la frustración, con sus respectivas secuelas de corrupción administrativa y alcoholismo, condicionan, para Díaz Chávez, el hecho sociológico más notable: "la sociología de la revolución armada" ${ }^{72}$

En la misma línea de Valle y Ramón Rosa, este autor centra el problema de la integración y el vínculo social hondureño en el tema de la guerra, y sobre todo en la revuelta. Sin embargo, a diferencia de Rosa ubica el problema de la desintegración social hondureña en la tensión que se da entre la rebeldía y la explotación, especialmente por la base material de una economía agraria deformada por el escaso acceso de los hondureños a la propiedad de la tierra. Sobre esta base, Díaz Chávez construye una compleja matriz de interpretación de la sociedad hondureña, que denomina "el proceso de sociología bárbara". En efecto, considera que la colonización representa la entronización en Honduras de

\footnotetext{
69 Loc. cit.

70 Ibid., p. 392.

${ }^{71}$ Loc. cit.

72 Loc. cit.
} 
la esclavitud y del feudalismo, que liquidaron lo que él llama "la conciencia social alegre de los antepasados mayas". La pérdida de la propiedad colectiva por parte de los indígenas ha implicado que la estructura socioeconómica de Honduras haya tenido escaso desarrollo, sobre la base de una población explotada y con una gran concentración del poder económico en una oligarquía nacional.

El problema de la propiedad de la tierra ha originado en Honduras un espacio tensor, es decir, "ascenso de la explotación feudal de la tierra, las crecidas tasas de alquiler de casas, la expropiación hipotecaria de grandes sectores de la población, las marchas forzosas de la movilidad geográfica, la intensidad de la ley famélica, la mutilación urbana, la red caminera deficiente, etcétera, todo lo cual no es sino aumento de la proletarización de los habitantes hondureños, desintegración social y económica". ${ }^{73}$

El hambre es el hecho sociológico más significativo de la realidad hondureña. Dada la estructura latifundista del país, Díaz Chávez concluye que en él se aplica una "ley famélica" propia de las regiones subdesarrolladas:

Ella expresa que el hambre, como hecho sociológico, tiene su matriz fecunda en el orden social interno, y cuyas bases son el latifundismo y el imperialismo. Este vástago exuberante del estéril suelo feudal, abonado y cultivado por la sujeción a la metrópoli yanqui, la imposición de una política económica de exclusivo beneficio capitalista de la oligarquía abrazada a los monopolios extranjeros, no sólo disminuye la talla y el peso del cuerpo famélico [...] sino que modela, talla y trabaja las vísceras espirituales, la estructura mental, la conducta social, la tristeza secular, el alcoholismo ligado a éste, la indiferencia y la apatía, son unos pocos ejemplos de la conducta conformada por el hambre crónica. ${ }^{74}$

Si bien para el autor se establece una suerte de dialéctica entre el hambre y la rebeldía, esta última no es más que una rebeldía famélica,

74 Ibid., p. 409. 
incapaz de generar transformaciones importantes. Puede decirse que es una rebeldía sin causa, cuyas manifestaciones no son más que la reproducción de las condiciones sociales de atraso y desintegración:

Ambas raíces de la miseria condicionan mayores reacciones parásitas, traducidas en anarquía, corrupción administrativa, alcoholismo, conformismo, para finalmente llegar a las revueltas intestinas que ha padecido el país, volviendo éstas, a su vez, más tenso el original atraso económico y social y, por consiguiente, aumentando el subdesarrollo. ${ }^{75}$

La ley famélica, como fenómeno social, y la existencia objetiva del régimen latifundista-mercantil y su penetración por el imperialismo, se expresa en su forma económica en la falta de producción en general, y, en particular, de alimentos.

Así, la tesis fundamental de Díaz Chávez es que el régimen económico subdesarrollado de Honduras - como producto de la deformación en la tenencia de la tierra y, posteriormente, la desfiguración capitalista interna y la penetración extranjera - es el causante de la injusticia social; de ahí que el hambre y la rebeldía contra la explotación sean las dos consecuencias más inmediatas de esa injusticia, y a su vez sean dos situaciones que catapultan y explican el hecho social más significativo de la historia de Honduras: las guerras internas, producto de la anarquía del hondureño: "En un estadio más exacerbado, la anarquía, junto con la frustración, desprendimiento directo de la raíz sociológica del hambre, determinan las luchas armadas intestinas". ${ }^{76}$

La inestabilidad política propia de la historia del país es producto de la anarquía, la cual tiene su origen en la estructura social que provoca el subdesarrollo económico. Pero la consecuencia mayor de ésta ha sido la corrupción administrativa: "A mayor inestabilidad política, mayor inmoralidad política, y a mayor inmoralidad política, mayor inestabilidad política". ${ }^{77}$ 
Para Díaz Chávez, la constante inestabilidad política tiene su causa en la ausencia de una actividad económica desarrollada. Ello a su vez ha provocado una deformación de la superestructura en el expansionismo de la actividad política, que termina definiéndose más bien por el asalto al poder de grupos oligárquicos.

\section{CONCLUSIONES}

La teoría de la historia en Honduras ha tenido pocos pensadores que se hayan hecho cargo de ella. No todos los que se han dedicado al estudio de la historia se han ocupado de hacer una reflexión teórica sobre su campo de estudio. De hecho, dentro de la historiografía hondureña predominan estudios empíricos, carentes de marcos interpretativos o que respondan a ciertas escuelas de pensamiento. Esta reflexión teórica sobre la historia ha correspondido a personajes con un pensamiento erudito u holístico como son el caso de José Cecilio del Valle, Ramón Rosa y Filánder Díaz Chávez.

Por otra parte, es importante decir que no todas las corrientes teóricas o escuelas de pensamiento histórico han tenido influencia en el país. No existe dentro de la historiografía sobre Honduras ningún estudio escrito en perspectiva estructuralista o mucho menos desde las actuales visiones posmodernas. De hecho la producción historiográfica continúa inscribiéndose en una perspectiva positivista del progreso y en escribir la historia como la suma de hechos y no como puede entenderse hoy en día, que la historia es un lenguaje o relato en el que hay que buscar su significado.

Fue Ramón Rosa el que más influyó, con su teoría de la historia positivista, en la producción de un conocimiento histórico como la suma de hechos y en clave de progreso. Desde su función como ministro durante el gobierno de Marco Aurelio Soto (1846-1908) fue el primero en encargar escribir una historia de Honduras con esta perspectiva. Asimismo dos de los principales historiadores hondureños de la primera 
mitad del siglo Xx fueron sus discípulos, Rómulo E. Durón y Esteban Guardiola.

Este trabajo sobre la teoría de la historia en Honduras es más bien aproximativo y no conclusivo, queda mucho por investigar, sistematizar y documentar para poder adentrarse con mayor profundidad en el pensamiento del cual se han servido efectivamente los historiadores hondureños para orientar su trabajo. Así como de las ideas que contiene el proyecto social en que han inscrito su tarea.

BIBLIOGRAFÍA

Argueta, M., Tendencias e investigaciones recientes de la sociología Hondureña: un ensayo bibliográfico, Tegucigalpa, Editorial Universitaria, 1981.

Belabal, Y., Racionalismo, empirismo, ilustración, México, Siglo XXI, 1984.

CAstillo, RoBerto, Filosofía y pensamiento hondureño, Tegucigalpa, Editorial Universitaria, 1992.

DíAz CHÁvez, F., Sociología de la desintegración regional, Tegucigalpa, Dirección de Extensión Universitaria-UNAH, 1972. La independencia de Centroamérica. Dilatado proceso histórico por la liberación nacional, Tegucigalpa, FEUH, 1973.

ESCOBAR VALENZUELA, G., "La ilustración en la filosofía latinoamericana”, en J. Fontana, Historia. Análisis del pasado y proyecto social, Barcelona, Crítica, 1982.

Gallo, M., ¿Qué es la historia?, México, Quinto Sol, 1989.

GONZÁLEZ-CARVAJAL, J., Ideas y creencias del hombre actual, España, Sal Térrea, 1988.

GonzÁlez Rojo, E., Teoría científica de la historia, México, Diógenes, 1978.

GODELIER, M., Racionalidad e irracionalidad en la economía, México, Siglo XXI, 1967. 
Gunder Frank, A., "Desarrollo del subdesarrollo", Suplemento de la Revista Tlatoani, México, 1970, p. 54.

Habermas, J., Conocimiento e interés, Madrid, Taurus, 1982.

Nisbet, R., Historia de la idea de progreso, Barcelona, Gedisa, 1980.

Perdomo, C., Pensamiento positivista liberal de Ramón Rosa, Tegucigalpa [s. e.], 1994.

OQuelí, R. "La historia no se cansa", Revista Historia Crítica, Etapa I, núm. 6, Tegucigalpa, UNAH, 1991.

, Los hondureños y las ideas, Tegucigalpa, Editorial Universitaria, 1986.

"Algunos inéditos de José Cecilio del Valle", en Escritos inéditos de José Cecilio del Valle, Tegucigalpa, scA/Universidad José Cecilio del Valle/UNESCO, 1996.

RosA, RAmón, Obra escogida, Tegucigalpa, Guagmuras, 1980.

Las batuecas y otros escritos, Tegucigalpa, Universitaria, 1985.

Sierra FonseCA, R., La filosofía de la historia de José Cecilio del Valle, Honduras, Subirana, 1998.

Colonia, independencia y reforma. Introducción a la historiografía hondureña, Tegucigalpa, Fondo Editorial de la Universidad Pedagógica Nacional, 2001.

Valle, J. C., Pensamiento vivo de José Cecilio del Valle, introd., selec. y notas de Rafael Heliodoro Valle, San José, EDUCA, 1971.

, Obra escogida, introd., selec. y pról. de J. M. García Laguardia, Venezuela, Biblioteca Ayacucho, 1982.

, Antología, introd., selec. y notas de Ramón Oquelí, Tegucigalpa, Universitaria, 1981.

"Historia", 18 Conejo, Boletín literario de la editorial universitaria, núm. 19, Tegucigalpa, 19 de agosto, 1989, p. 4.

, Escritos inéditos de..., introd., selec. y notas de Ramón Oquelí, Tegucigalpa, SEC/Universidad José Cecilio del Valle/UnESCO, 1996.

VILlar, P., Iniciación al vocabulario del análisis histórico, Barcelona, Crítica, 1982.

ZELAYA, G., El legado de la reforma liberal en Honduras, Tegucigalpa, Guagmuras, 1993. 
